\title{
Real Time PCR: the Use of Reference Genes and Essential Rules Required to Obtain Normalisation Data Reliable to Quantitative Gene Expression
}

\author{
Antônio J. Rocha ${ }^{1}$, José E. Monteiro-Júnior ${ }^{2}$, José E.C. Freire ${ }^{1}$, Antônio J.S. Sousa ${ }^{1}$ \& Cristiane S.R. Fonteles ${ }^{3}$ \\ ${ }^{1}$ Departamento de Bioquímica e Biologia Molecular, Avenida Humberto Monte, s/n - Pici - CEP 60440-900, \\ Fortaleza - CE, Brasil \\ ${ }^{2}$ Departamento de Biologia, Avenida Humberto Monte, s/n - Pici - CEP 60440-900, Fortaleza - CE, Brasil \\ ${ }^{3}$ Departmento de Clínica Odontológica, Universidade Federal do Ceará, Rua Monsenhor Furtado, s/n - Rodolfo \\ Teófilo - CEP 60430-350, Fortaleza - CE, Brasil \\ Correspondence: Antônio J. Rocha, Departamento de Bioquímica e Biologia Molecular, Avenida Humberto \\ Monte, s/n - Pici - CEP 60440-900, Fortaleza - CE, Brasil. E-mail: antonionubis@gmail.com
}

Received: July 1, 2015 Accepted: July 15, 2015 Online Published: July 20, 2015

doi:10.5539/jmbr.v5n1p45 URL: http://dx.doi.org/10.5539/jmbr.v5n1p45

\begin{abstract}
Quantitative Real-time Polymerase Chain Reaction (qPCR) is an important tool for molecular biology and biotechnology research, widely used to determine the expression levels of mRNA. Two main methods to performing qPCR are largely used: The absolute quantification, in which the mRNA levels are determined by using a standard curve and the relative method, which is based on the use of reference genes. Reference genes are widely expressed in cells of animal and plant tissues and their expression pattern are theoretically unchanged within several situations, which makes them an excellent choice to normalize mRNA quantification data in relative qPCR studies. However, several reports are increasingly showing that the use of only one reference gene in relative qPCR studies should be avoided, because in the real world their expression levels can significantly change from tissue to tissue. Several softwares, such as geNorm, BestKeeper and NormFinder, have been developed to perform data normalisation, and these programs may assist in choosing the most stable reference genes. The aim of this review was to describe the current normalisation strategies used in qPCR assay, as well as to establish essential rules to perform reliable mRNA quantification. Finally, this review show some innovations in the advances on qPCR.
\end{abstract}

Keywords: primer design, DNA binding dyes, probes, normalisation

\section{Introduction}

The polymerase chain reaction (PCR) technique was first introduced by Kary Mullis (Saiki et al., 1985). PCR is historically used as a sensitive method for the detection and amplification of specific sequences of nucleic acids in a sample. Advances in the specificity and sensibility of PCR reactions gave birth to a more sensitive PCR technique, namely quantitative PCR (qPCR-quantitative real-time polymerase reaction), which utilizes mainly cDNA as template, a complementary DNA from RNA molecules through of the reverse transcriptase reaction. In these reactions, fluorescent reporters used include double-stranded DNA (dsDNA) binding dyes or probes that are incorporated into the product during amplification. The increase in fluorescent signal is directly proportional to the number of PCR product molecules generated in the reaction.

qPCR is amongst the best available methods to determining changes in gene expression, due their ability to rapidly and accurately quantify target genes, even in the presence of very low expression levels (Holland, 2002). Prior to the analysis of gene expression, the selection of an appropriate normalisation strategy is essential to control for non-specific variations between samples of cDNA. The most commonly used method to normalising qPCR data is relied on the use of one or more endogenous reference genes (Hamalainen et al., 2001; Rebouças et al., 2013).

Reference genes have uniform and stable expression in a wide variety of tissues and cell types, at different developmental stages, and comprise all genes that express protein products involved in basic cellular processes 
(Reid et al., 2006), showing none or only minimal changes in the expression levels between individual samples and experimental conditions (Rebouças et al., 2013). These genes are largely used as internal controls for normalisation in gene expression studies in different tissues and/or condition as in plants and animals (Wong et al., 2005; Kumar et al., 2013; Sara et al., 2013; Rocha et al., 2013; Nakayama et al., 2004). Several reference genes, including those coding for biological products such as tubulins, actin, glyceraldehyde-3-phosphate dehydrogenase (GAPDH), phosphatases, albumin, cyclophilin, micro-globulin, ribosomal units (18S rRNA) or ubiquitin (UBQ) have been described in the literature (Foss et al., 2003; Rocha et al., 2013). The correct choice of reference genes is crucial to properly analyze the results of qPCR (Suzuki et al., 2000) and to measure and reduce the errors from variations among the samples (Barsalobres-Cavallari et al., 2009).

Several research groups have developed software tools to identify the most stable expressed genes across a set of samples in order to perform data normalisation. These tools include geNorm, NormFinder and BestKeeper (Vandesompele et al., 2002; Pfaffl et al., 2004; Andersen \& Orntoft, 2004), which is freely available on the web and allows researchers to find the best reference gene for their experiments. A great number of studies describing the identification of multiple reference genes for normalisation of qPCR data using these algorithms have been performed on the animal and human health fields (Hong et al., 2008; De Boever et al., 2008), but similar reports are scarce in plant research (Jain et al., 2006; Ransbotyn et al., 2006; Exposito-Rodriguez et al., 2008).

The aim of this review was to evaluate the importance of the application of reference genes in normalisation strategies of qPCR assays, in different tissues or experimental conditions, as well as to describe essential rules necessary to conduct successful qPCR experiments. Besides, we pointed out several precautions required for a good qPCR. Finally, this review shows some innovations in the advances on qPCR in the last years.

\section{DNA Binding Dyes Versus Hydrolysis Probes in qPCR}

PCR is one of the most versatile technologies in molecular biology. The PCR reaction consists of 3 different stages which involve, (a) the DNA denaturation; (b) the primer annealing and (c) the extension phase (Mullis et al., 1987). In traditional (endpoint) PCR, the detection and quantification of amplified target sequences are performed at the end of the reaction, and it involves additional work, such as gel electrophoresis and image analysis. Nevertheless, in qPCR, the amount of PCR product is measured along each reaction cycle. The ability to monitor the reaction during its exponential phase enables users to determine the initial amount of target gene with great precision (Wong et al., 2005).

In qPCR, the amount of DNA is measured by the use of fluorescent markers that are incorporated into the PCR product. The increase in fluorescent signal is directly proportional to the number of PCR product molecules (amplicons) generated in the exponential phase of the reaction. Fluorescent reporters used include double-stranded DNA (dsDNA) binding dyes or probes that are incorporated into the product during amplification (Bustin et al., 2002). SYBR Green is an example of a fluorescent dye which binds to the double-stranded DNA and emits light upon excitation. Once the reaction proceeds and the PCR product is accumulated, the fluorescence levels increase proportionally to the amount of DNA present in the original sample (Livak et al., 1995; Pabla et al., 2008; Bustin et al., 2002). This dye is used to monitor the amplification of any DNA sequences and dispenses the use of a probe, thus reducing the cost of amplification and providing a great advantage in its application. On the other hand, since the dye binds not only to the target DNA, but to all dsDNA formed during qPCR, the use of SYBR Green, while simple lacks specificity (Figure 1a). The specificity of the reactions, however, can be easily accessed by the use of melting curve analysis (Dheda et al., 2004).

In addition to DNA binding dyes, there are probes, such as TaqMan ${ }^{\circledR}$, which are designed to binds to specific DNA sequences. TaqMan ${ }^{\circledR}$ probes primarily consist in a oligonucleotide sequence complementary to some regions of the target DNA. The probe is complexed with a quencher and a reporter fluorophore dye at its $3^{\prime}$ and $5^{\prime}$ ends, respectively (Livak et al., 1995). During the amplification step the probe is associated to its complementary target DNA and then is cleaved by Taq DNA polymerase 5'-3' exonuclease activity (Figure 1b). This cleavage releases the reporter dye and generates a fluorescent signal that increases with each cycle (Bustin et al., 2002). TaqMan ${ }^{\circledR}$ provides higher specificity than DNA intercalating dyes, such as SYBR Green. In addition, these probes can also be labeled with distinct and distinguishable reporter dyes, which allows the amplification of two different sequences in the same reaction tube, eliminating the post-PCR processing, and reducing hand labor. The main drawback of this system is the requirement to synthesize specific probes to each target sequences, increasing the cost of the assay (La Cruz et al., 2013).

Another type of probe which is largely used in qPCR assay is molecular beacon. When free in solution molecular beacon probes assume a hairpin structure consisting of a quencher and a reporter dye (Tyagi et al., 1996). The reporter fluorescent dye and the quencher remain extremely close and therefore no fluorescence is detected when 
this structure is formed (Figure 1c). However, during the annealing step, Molecular Beacon hybridizes to the target sequence generating conformational changes leading to the separation of reporter and quencher dyes, which results in the emission of fluorescence (Tyagi et al., 1996; VanGuilder et al., 2008). The greater specificity for mismatch discrimination is due to structural constraints. However, the main disadvantage associated with Molecular Beacons is the accurate design of the hybridization probe. Optimal design of the Molecular Beacon stem annealing strength is crucial (Wong et al., 2005).

Scorpions consist of a single-stranded oligonucleotide probe of approximately 20 to $25 \mathrm{nt}$ carrying a reporter fluorophore at its $5^{\prime}$ end and a quencher at its $3^{\prime}$ end. Their tridimensional conformation resembles a stem and loop structure, in which a PCR primer is attached (figure 1d). The stem-and-loop structure acts as a blocker to prevent DNA polymerase activity during the interaction of the probe with the target DNA (Bustin et al., 2002; $\mathrm{Ng}$ et al., 2005). The close proximity of the reporter to the quencher leads to a continuous suppression of the fluorescence emitted by the reporter. At the beginning of the PCR, TaqDNA polymerase extends the PCR primer and synthesizes the complementary strand of the target sequence (Whitcombe et al., 1999). During the next cycle, the stem-and-loop structure unfolds and the loop region of the probe hybridizes intra-molecularly to the newly synthesized target sequence. The reporter is excited by light from the qPCR instrument (Bustin et al., 2002). Once the reporter dye is no longer in close proximity to the quencher dye, fluorescence emission may take place. The significant increase of the fluorescent signal is detected by the qPCR instrument and it is directly proportional to the amount of target DNA (Holland, 2002; Wong et al., 2005; Kumar et al., 2013). Scorpions have the advantage to providing a stronger signal and lower level of background when in compared to other probes, such as molecular beacons (Bustin et al., 2002).
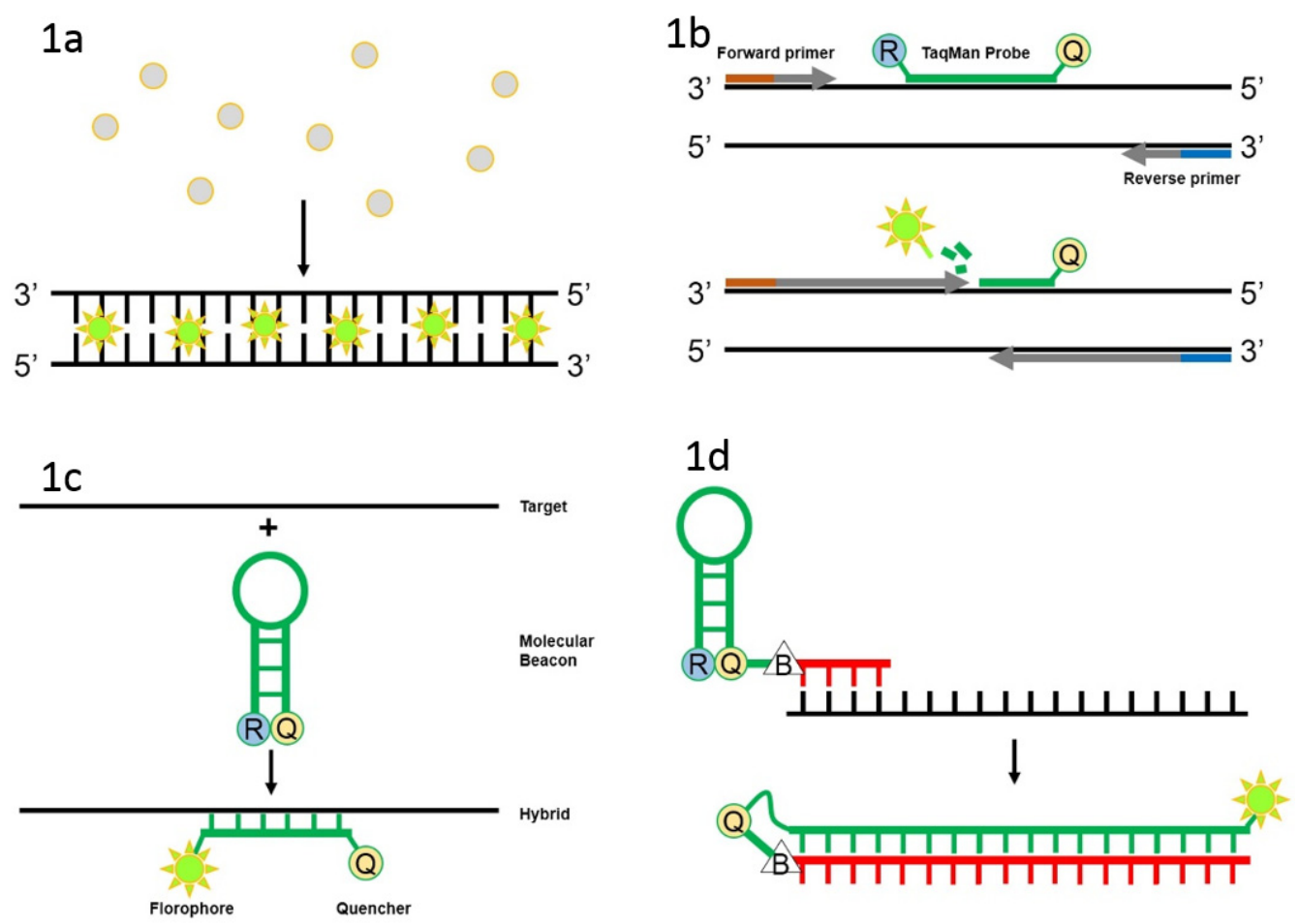

Figure 1. Probes and Dyes used in Real time PCR assay; a) SYBR Green; b) TaqMan; c) Molecular Beacon; d) Scorpions

\section{The Use of Reference Genes to Normalize qPCR Data}

Reference genes in qPCR are critical for normalisation of expression levels, thus, avoiding misinterpretation of results obtained by real time PCR data. In recent years, it has become clear that no single gene is constitutively expressed in all cell types and under all experimental conditions. This implies that the expression stability of a putative control gene (reference gene) must be verified before each qPCR assay and that the use of only one reference gene is generally not enough to normalize the expression data (Livak et al., 2001; Lee et al., 2010). 
The choice of several reference genes to normalize and validate the final results may significantly influence the accuracy of gene expression. Consequently, the use of inappropriate reference genes for normalisation of expression data may lead to erroneous results and data misinterpretation (Suzuki \& Higgins, 2000), because normalisation is a pivotal step that provides the Cq values-based differences between the reference and target genes, avoiding misinterpretation of the results and providing reliable Cqs, thus rendering a more accurate and reliable gene expression (Vandesompele et al., 2002). The Ct or threshold cycle value is the cycle number at which the fluorescence generated within a reaction crosses the fluorescence threshold, a fluorescent signal significantly above the background fluorescence. Therefore, the selection of appropriate reference genes is a critical step before evaluating gene expression in new species and/or tissues (Condori et al., 2001; Cordoba et al., 2001). The best candidate genes are those selected by programs used to establish reference genes, such as geNorm, BestKeeper and NormFinder. Therefore, the normalisation using appropriated reference genes are pivotal to acquire suitable data and avoid and misinterpretation of the experiments.

\section{Algorithms Used to Normalize qPCR Data}

In the last decade, relevant tools to select genes for normalisation have become available. Several research groups have developed softwares to identify the most stably expressed genes across a set of samples. Among these tools we will focus on the most cited articles as geNorm, NormFinder and Bestkeeper (Vandesompele et al., 2002; Andersen \& Orntoft, 2004; Pfaffl et al., 2004), which are freely available on the web and allow researchers to find the best reference gene for their experiments. These programs allow the calculation of a normalisation factor over multiple reference genes, which improve the robustness of the normalisation even further (Dekkers et al., 2012). Different manners to access the stability of putative reference genes are available using the upon mentioned software. Hence, BestKeeper employs quantification cycle $\left(\mathrm{C}_{\mathrm{q}}\right)$ values directly for stability calculations, whereas geNorm and NormFinder have these values transformed to relative quantities using normalisation factor (NF) (Mallona et al., 2004).

\subsection{Genorm Analysis}

The geNorm program has been recently reported to be one of the best statistical methods to identify stably expressed genes for qPCR analysis. The geNorm calculates a gene-stability measure $M$ as the Average pairwise variation $V$ of a particular gene reported to all other control genes. Genes with the lowest $M$ values have the most stable expression. Stepwise exclusion of the gene with the highest $M$ value allows ranking of the tested genes according to the stability (Condori et al., 2001; Cordoba et al., 2001; Vandesompele et al., 2002; Zhong et al., 2009). The analysis relies on the principle that the expression ratio of two proper control genes should be identical in all samples, regardless of the experimental conditions or cell type, and the $\mathrm{M}$ values below cutoff $(<1.5)$ are regarded the most stable genes among all candidate reference genes (Vandesompele et al., 2002).

The geNorm program estimates also the number of genes required to be used as appropriate controls for normalisation by evaluation of variation in pairs ( $\mathrm{V}$ values), checking the variation of the expression of two by two possible genetic combinations. The optimal number of reference genes that should be used for accurate normalisation also depends on the specific experimental condition, which is determined by calculating $\mathrm{V}$-values as a pairwise variation $(\mathrm{Vn} / \mathrm{Vn}+1)$ between two consecutively ranked normalisation factors (NF) after the stepwise addition of the subsequent more stable reference gene (NFn and NFn+1) (Vandesompele et al., 2002). Actually, the geNorm is part of qBASEPlus (Biogazelle) program as tool important to provide the reference genes more stables ( $\mathrm{M}$ value) and the number of genes suitable to normalisation (V value). Furthermore, the qBASEPlus (Biogazelle) also provides the relative expression on qPCR experiments based on the normalisation factor (NF). The use of the qBASEPlus (Biogazelle) is needed at least 8 reference genes and at least 2 samples (control and conditions) for to analyze the qPCR data.

\subsection{Normfinder Analysis}

The NormFinder is an algorithm used to identify the optimal normalisation gene among a set of candidates. It ranks the set of candidate normalisation genes according to their expression stability in a determined sample set and given experimental design. This algorithm is rooted in a mathematical model of gene expression and uses a solid statistical framework to estimate not only the overall expression variation of the candidate normalisation genes, but also the variation between sample subgroups of the sample set e.g. normal and cancer samples (Andersen \& Orntoft, 2004). Notably, "NormFinder" provides a stability value for each gene, which is a direct measure for the estimated expression variation, enabling the user to evaluate the systematic error introduced when using the gene for normalisation (Dekkers et al., 2012; Selim et al., 2012). 


\subsection{Bestkeeper Analysis}

The BestKeeper calculates standard deviation (SD) and the coefficient of variation (CV) based on Cq values of all reference candidate genes. Genes with SD less than 1 are considered stable. Subsequently, the program calculates a pairwise correlation coefficient between each gene and the BestKeeper index-geometric mean between $\mathrm{Ct}$ values of stable genes grouped together. Genes with the highest coefficient of correlation with the BestKeeper Index indicates the highest stability (Pfaffl et al., 2004). The BestKeeper use raw Ct data and determines the most stably expressed genes based on a correlation coefficient (r) of the BestKeeper Index (BI) and standard deviation, whereas BI is the geometric mean of $\mathrm{Ct}$ values of best reference genes. Hence, this program relies on the " $r$ " and "SD" values, and the higher the " $r$ " value, the most stable is the gene; otherwise, the lower the standard deviation value, the most stable is the gene (Pfaffl et al., 2004; Demidenko et al., 2011; Niu et al., 2011; Petit et al., 2012).

These statistical algorithms have been developed for the evaluation of best suited reference gene(s) for normalisation of qPCR data in a set of biological samples. Recognizing the importance of reference genes in normalisation of qPCR data, various reference genes have been evaluated for their stable expression under specific conditions in various organisms. Many studies have been conducted in the animal and human health (De Boever et al., 2008; Hong et al., 2008) fields that describe the identification of multiple reference genes for normalisation of qPCR data, but similar reports are scarce in plant research (Ransbotyn et al., 2006; Exposito-Rodriguez et al., 2008).

The three algorithms are important for reference gene stability and normalisation data during qPCR experiments; however, geNorm is the best tool since in addition to providing the best reference genes in geNorm $\mathrm{M}$, this software supplies the $\mathrm{V}$ value, which delivers the number of genes needed for use in normalisation data in a qPCR experiment. The algorithms NormFinder and BestKeeper will only identify the most stable genes. Generally, all three algorithms are used to render more reliable results for normalisation.

\section{Essential Rules Required to Perform a Reliable qPCR}

The efficiency and specificity of quantitative PCR depends on several parameters related to quantification of mRNA, which must be controlled to avoid errors of interpretation: purification of RNA, efficiency of primer specifics, normalisation of reference genes, tissue inhibitory factors, enzyme loading error (Rocha, Miranda, \& Cunha, 2014), pipetting errors, among others (Thellin et al., 1999; Livak et al., 2001; Suzuki et al., 2000; Vandesompele et al., 2002) as described below.

\subsection{Primers and Probes Design Considerations}

The primers and probes design are essentials for amplification efficiency, specificity and fluorescence, respectively. The primers are specially needed in junction exon-exon to avoid an amplification of DNA genomic, ensuring the amplification of only a target gene specific cDNA sequence. In addition, it may be necessary to digest input DNA with an RNase free DNA in the following circumstances: (1) to avoid DNA amplification during qPCR; (2) to use primers that either flank an intron that is not present in the mRNA sequence or that span an exon-exon junction; (3) when the gene of interest has no introns; (4) if the intron positions are unknown; (5) when there are no suitable primers that span or flank introns (Udvardi et al., 2004). There are several programs used to design automatic primers, such as Perl Primer (Marshall, 2004) that will require previous annotation of genes, establishing the introns and exons of each sequence to input the program. Other programs are available in the web as primer BLAST, a tool available at http://www.ncbi.nlm.nih.gov/tools/primer-blast/index.cgi?LINK_LOC=BlastHome in the GenBank of NCBI, as well as Primer3 Plus available at http://www.bioinformatics.nl/ cgi-bin/primer3plus/primer3plus.cgi/. Moreover, an absence of primer-dimer and non-specific amplification is especially important to suitable data of qPCR. Therefore, the presence of homo-dimers, hetero-dimers, as well as self-dimers must be avoided, and the formation of harpin of a forward or reverse primer (Condori et al., 2001; Rocha et al., 2013).

The probes, such as TaqMan ${ }^{\circledR}$, Molecular beacon and scorpions are primers marked with fluorophores to emit fluorescence. These probes are designed in different forms, but are used with the common purpose of emitting fluorescence to assess the increase on gene expression due to the number of probes that bind a double-stranded DNA (Bustin et al., 2002; Pabla et al., 2008; VanGuilder et al., 2008; Hwang et al., 2013). There are programs, such as primer BLAST, available in the GenBank of NCBI, as well as Primer3 Plus both available in the web. These are the same programs used to design primers and probes (Condori et al., 2001).

\subsection{RNA Quality}

The quality of RNA also is very important to provide accurate qPCR data. The quality of RNA depends on extraction and purification of RNA, for example, during the extraction of RNA contaminants such as proteins, 
carbohydrate, as well as phenolic compounds that will affect the PCR reaction by inhibiting the action of polymerases as reverse transcriptase and DNA polymerases, during qPCR must be avoided. Therefore, RNA of good quality is needed for further experiments. According to Sambrook et al. (1989), the best relations absorbance by spectrophotometer are as follows: RNA relation to $\mathrm{A}_{260 / 280}$ : 1.8-2.0, which is the acceptable limit of contamination with proteins, and $\mathrm{A}_{260 / 230}$ : $>2,0$ for contamination with carbohydrates. These data have also been reported by Sambrook et al. (1989) and Romano (1998). Furthermore, to avoid contamination with genomic DNA, Digest purified RNA with DNase I is needed to remove contaminating genomic DNA, which can act as template during PCR and may lead to spurious results. It may also be necessary to perform PCR on the treated RNA, using gene-specific primers, to confirm absence of genomic DNA (Udvardi et al., 2008).

To complete a reliability of the extracted and purified RNA, the integrity of the RNA requires evaluation. The measure of RNA reliability is based on the integrity of $28 \mathrm{~S}$ and $18 \mathrm{~S}$ ribosomal RNA and the lack thereof shows a smear in the agarose gel, indicating that the total RNA is degraded. Thus, an electrophoresis in agarose gel at $0.8 \%$ to $1.0 \%$ is recommended to observe the integrity of the ribosomal RNA bands (Sambrook et al., 1989).

\subsection{Optimization and Efficiency Curve of Primers}

Other parameters such as the optimization of primer concentrations and efficiency primer curves that might be done in serial dilutions or standard curves are important to perform qPCR assays. A dilution series of known template concentrations can be used to establish a standard curve for determining the initial starting amount of the target template or for assessing the reaction efficiency. The log of each known concentration in the dilution series is plotted against the $\mathrm{Cq}$ value for that concentration. Information on the performance of the reaction as well as various reaction parameters (including slope, y-intercept, and correlation coefficient) can be derived from this standard curve. The slope is obtained by the linear equation of the graph constructed by plotting the Cq values on the $y$-axis and the log values of the dilutions on the x-axis. The concentrations chosen for the standard curve should encompass the expected concentration range of the target (Pfaffl et al., 2004). At the end of the qPCR assay, primer efficiency must be calculated, and the formula most frequently described in the literature for this purpose is as follows: Efficiency $=10^{(-1 / \text { slope })}-1$, in which the slope corresponds to the $\mathrm{C}_{\mathrm{q}}$ value of the first dilution (concentration dilution) minus the $\mathrm{C}_{\mathrm{q}}$ value of the last dilution divided by the number of dilutions. Hence, if the PCR is $100 \%$ efficient, the amount of PCR product will double with each cycle and the slope of the standard curve will be -3.33 $\left.\left(100=100 \%=10^{(-1 / 3.33}\right)-1\right)$. The ideal slope is approximately -3.33 cycles; however, a slope between -3.9 and -3.0 (80-110\% efficiency) is generally acceptable (Livak et al., 2001; Pfaffl et al., 2004). Calculated levels of target input may not be accurate if the reaction is not efficient. In order to improve efficiency, one must consider either (1) optimize primer concentrations or (2) design alternative primers.

Since SYBR Green binding dye is a non-specific dye that will detect any double-stranded DNA, it is important to verify if the qPCR is producing only the desired product. This can often be detected when PCR efficiencies are larger than 120\% (Bustin et al., 2002; Bustin et al., 2009). Melting or dissociation curve is expressed during the last step of qPCR, following 40 cycles that only show one peak, revealing that a single multigene family isoform was amplified. These analyses can also be used to determine the approximate product size (Udvardi et al., 2004). If the melting curve has more than one major peak, the identities of the products should be determined by fractionating them on an ethidium DNA agarose gel electrophoresis to check for the presence of non-specific annealing. It must also be mentioned that lowering the primer concentrations will often reduce the amount of non-specific products. If the use of low primer levels still allow the detection of non-specific products in significant amounts, primer redesign may be a necessary measure. Once all cycles have been completed, the melting curve is added to evaluate the specificity of the primers. Melting curves with peaks lower than $78^{\circ} \mathrm{C}$ could indicate the presence of primer dimmers in the reaction or alternatively smaller non-specific amplicon products (Condori et al., 2001).

\subsection{Normalisation and Analysis of $q P C R$ Results}

In gene-expression profile quantification, an assessment of the reliability of qPCR assay is required to normalize the target gene expression data. One of the most frequently used methods is the utilization of reference genes. Previous to the qPCR assay, it is necessary to design primers that amplify constitutive genes. The groups of reference genes are checked for stability to identify the most stable reference genes among all the selected genes that will be used to normalize the qPCR data, using programs such as geNorm, BestKeeper and NormFinder. Once the best reference genes are identified, data normalisation is required to ensure gene expression reliability (Zhong et al., 2011). Likewise, to confirm reliability of the results, biological and technical replicates must be obtained to provide data statistics, and evaluate the significance levels of gene expression analysis (Udvardi et al., 2004). 
Relative quantification describes a real-time PCR experiment in which the gene of interest in one sample (i.e., treated) is compared to the same gene in another sample (i.e., untreated). The results are expressed as fold up- or down-regulation of the treated in relation to the untreated gene. Reference genes such as $\beta$-actin, GAPDH, elongation factor, among others are used as a control for experimental variability in this type of quantification (Tong et al., 2009). The most frequently used method for relative mRNA quantification by real time PCR has been described by Livak et al. (2001). This is a convenient method which presents the advantage of eliminating the need for standard curves. Thus, mathematical equations are used to calculate the relative expression levels of target relative to reference control or calibration, such as an untreated sample or RNA from normal tissue or a sample at time zero at qPCR experiments in time-course study. The amount of target gene in the sample normalized to a reference gene, relative to the normalized calibrator, is then given: $2^{-\Delta \Delta C q}$, where $\Delta \Delta \mathrm{C}_{\mathrm{q}}=\Delta \mathrm{C}_{\mathrm{q}}$ (sample)- $\Delta \mathrm{Cq}$ (calibrator), and $\Delta \mathrm{C}_{\mathrm{q}}$ is the $\mathrm{C}_{\mathrm{q}}$ of the target gene subtracted from the reference gene $\mathrm{C}_{\mathrm{q}}$, as describe by (Livak et al., 2001; Schmittgen et al., 2000; Schmittgen et al., 2008). In order to obtain reliable results, the target and reference gene must be approximately equal, and preferably at a percentage greater than $90 \%$. This level of sequence equality is necessary to plot an efficiency curve based on the dilution serial method to given suitable results in experimental data, as described above. Finally, statistics methods, including student t-test, ANOVA, among others, must be applied to the concluding analysis. However, this method of Livak et al (2001) is limited due the use of only one reference gene. Actually, has been used more than one reference genes to normalisation data qPCR using algorithm that is based in the normalisation factor (NF) method, as geNorm, BestKeeper and NormFinder (Vandesompele et al., 2002; Andersen \& Orntoft, 2004; Pfaffl et al., 2004) as described above.

\section{Several Advances on the Real Time PCR}

Several researchers are developing techniques to improve the quality of detection of DNA fluorescence. Recently, the manufacturer ELITE MGB ${ }^{\mathrm{TM}}$ has done a revolutionary advance in qPCR chemistry. The principle is based in the proprietary of the protein called Minor Groove Binder (MGB), Superbases ${ }^{\mathrm{TM}}$ and Eclipse ${ }^{\circledR D}$ Dark Quencher technologies. These overlapping probes are much efficiently and accurately detect target DNA sequences, while offering greater sensitivity and specificity. According to manufacturer, the MGB protein is a synthetic molecule that binds to the minor groove of double stranded DNA molecules. In qPCR applications, MGB increases the stability of double stranded DNA complexes, specifically, the hybridization between the probe and the amplified DNA target. The increased DNA-DNA hybrid stability allows the design of shorter detection probes with higher specificity. Furthermore, The Eclipse ${ }^{\circledR D}$ ark Quencher is a proprietary fluorophore and dye quencher chemistry resulting in low background signals. Its key benefit is to ensure that every ELITe MGB $^{\mathrm{TM}}$ assay will have the highest sensitivity by minimizing background signal interference. Together, show Real-Time PCR results of high accuracy.

Other works have shown important improving in the qPCR. Zheng et al. (2011) designed an aptamer-based sensing platform using a triple-helix molecular switch (THMS). The THMS consists of a central, target-specific aptamer sequence flanked by two arm segments and a dual-labeled oligonucleotide serving as a signal-transduction probe (STP). The STP is doubly labeled with pyrene at both ends and designed as a hairpin-shaped structure. Initially, the loop sequence of the STP binds with two arm segments of the aptamer, which forces the STP to form an "open" configuration and separate the two end labeled pyrene molecules, thus only emitting monomer fluorescence signal. The formation of the aptamer/target complex releases the STP, which switches to a "closed" hairpin configuration, bringing two pyrene molecules in close proximity and emitting excimer fluorescence signal. Hu et al. (2014) developed a modified Molecular Beacons-based multiplex qPCR Assay. In their work, all sets of primers and probes were combined, and the concentration of each reagent including primers, probes, magnesium, and Taq polymerase concentrations in the reaction mix were optimized. These modifications helped the sensitivity and specificity of the qPCR multiplex that were $100 \%$ and $99 \%$, respectively.

Any need for fast and precise measurement of small amounts of nucleic acids represents a potential future niche for real-time PCR-based innovations. As machines become faster, cheaper, smaller, and easier to use through competition, standardized assay development, and advances in microfluidics (Mitchell et al., 2001), optics, and thermocycling, more in-field application needs are likely to be filled. In the commercial food industry and agriculture, real-time PCR will likely see expanded use for the detection and identification of microbes, parasites, or genetically modified organisms. Forensics will benefit from real-time PCR's sensitivity, specificity, and speed, especially because time is crucial to many criminal investigations and specimen size may be limited. Reduced cost and increased portability open the door for the diagnosis of diseases in remote areas along with on-site epidemiological studies and may facilitate the transfer of needed scientific technologies to developing countries, thereby contributing to their "scientific capacity". 


\section{Final Considerations}

The polymerase chain reaction (PCR) is one of the most powerful technologies in molecular biology. qPCR is an efficient tool to measure the levels of mRNA expression in different types of samples; their use together with the reference genes are ideal for decreasing the possible errors in RNA extraction and contamination during sample manipulation, thus increasing the quality of cDNA. The qPCR has the sensible technical power to amplify target specific genes, but it is necessary to obtain reliable results in the gene expression profile. Several parameters must be considered, including good design of primers, evaluating their specificity and efficiency. In addition, the RNA extracted must be free of contaminants, such as carbohydrates, proteins and phenols, because these may interfere with the polymerases during PCR reaction. For the normalisation of qPCR data, the use of reference gene is needed to provide suitable results and reproducibility. Thus, the selection of a reference gene for each experimental condition is crucial. These precautions are pivotal to render reliable results during gene expression analysis.

\section{Acknowledgements}

The authors are grateful to CNPq and CAPES. This work was supported by the Universidade Federal do Ceará-UFC.

\section{References}

Andersen, C. L., Jensen, J. L., \& Ørntoft, T. F. (2004). Normalization of real-time quantitative reverse transcription-PCR data: a model-based variance estimation approach to identify genes suited for normalization, applied to bladder and colon cancer data sets. Cancer research, 64(15), 5245-5250. http://dx.doi.org/10.1158/0008-5472.CAN-04-0496

Barsalobres-Cavallari, C. F., Severino, F. E., Maluf, M. P., \& Maia, I. G. (2009). Identification of suitable internal control genes for expression studies in Coffea arabica under different experimental conditions. BMC molecular biology, 10(1), 1. http://dx.doi.org/10.1186/1471-2199-10-1

Bustin, S. A. (2002). Quantification of mRNA using real-time reverse transcription PCR (RT-PCR): trends and problems. Journal of molecular endocrinology, 29(1), 23-39. http://dx.doi.org/10.1677/jme.0.0290023

Bustin, S. A., Benes, V., Garson, J. A., Hellemans, J., Huggett, J., Kubista, M., ... \& Wittwer, C. T. (2009). The MIQE guidelines: minimum information for publication of quantitative real-time PCR experiments. Clinical chemistry, 55(4), 611-622. http://dx.doi.org/10.1373/clinchem.2008.112797

Condori, J., Nopo-Olazabal, C., Medrano, G., \& Medina-Bolivar, F. (2011). Selection of reference genes for qPCR in hairy root cultures of peanut. BMC research notes, 4(1), 392. http://dx.doi.org/10.1186/1756-0500-4-392

Cordoba, E. M., Die, J. V., González-Verdejo, C. I., Nadal, S., \& Román, B. (2011). Selection of reference genes in Hedysarum coronarium under various stresses and stages of development. Analytical biochemistry, 409(2), 236-243. http://dx.doi.org/10.1016/j.ab.2010.10.031

De Boever, S., Vangestel, C., De Backer, P., Croubels, S., \& Sys, S. U. (2008). Identification and validation of housekeeping genes as internal control for gene expression in an intravenous LPS inflammation model in chickens. Veterinary immunology and immunopathology, 122(3), 312-317. http://dx.doi.org/10.1016/j. vetimm.2007.12.002

Dekkers, B. J., Willems, L., Bassel, G. W., van Bolderen-Veldkamp, R. M., Ligterink, W., Hilhorst, H. W., \& Bentsink, L. (2012). Identification of reference genes for RT-qPCR expression analysis in Arabidopsis and tomato seeds. Plant and Cell Physiology, 53(1), 28-37. http://dx.doi.org/10.1093/pcp/pcr113

Demidenko, N. V., Logacheva, M. D., \& Penin, A. A. (2011). Selection and validation of reference genes for quantitative real-time PCR in buckwheat (Fagopyrum esculentum) based on transcriptome sequence data. PLoS One, 6(5), e19434. http://dx.doi.org/10.1371/journal.pone.0019434

Dheda, K., Huggett, J. F., Bustin, S. A., Johnson, M. A., Rook, G., \& Zumla, A. (2004). Validation of housekeeping genes for normalizing RNA expression in real-time PCR. Biotechniques, 37, 112-119.

Expósito-Rodríguez, M., Borges, A. A., Borges-Pérez, A., \& Pérez, J. A. (2008). Selection of internal control genes for quantitative real-time RT-PCR studies during tomato development process. BMC Plant Biology, 8(1), 131. http://dx.doi.org/10.1186/1471-2229-8-131

Foss, D. L., Baarsch, M. J., \& Murtaugh, M. P. (1998). Regulation of hypoxanthine phosphoribosyltransferase, glyceraldehyde - 3 - phosphate dehydrogenase and $\beta$ - actin mRNA expression in porcine immune cells and tissues. Animal biotechnology, 9(1), 67-78. http://dx.doi.org/10.1080/10495399809525893 
Hamalainen, H. K., Tubman, J. C., Vikman, S., Kyrölä, T., Ylikoski, E., Warrington, J. A., \& Lahesmaa, R. (2001). Identification and validation of endogenous reference genes for expression profiling of $\mathrm{T}$ helper cell differentiation by quantitative real-time RT-PCR. Analytical biochemistry, 299(1), 63-70. http://dx.doi.org/ 10.1006/abio.2001.5369

Holland, M. J. (2002). Transcript abundance in yeast varies over six orders of magnitude. Journal of Biological Chemistry, 277(17), 14363-14366. http://dx.doi.org/10.1074/jbc.C200101200

Hong, S. Y., Seo, P. J., Yang, M. S., Xiang, F., \& Park, C. M. (2008). Exploring valid reference genes for gene expression studies in Brachypodium distachyon by real-time PCR. BMC plant biology, 8(1), 112. http://dx.doi.org/10.1186/1471-2229-8-112

Hwang, S., Kang, B., Hong, J., Kim, A., Kim, H., Kim, K., \& Cheon, D. S. (2013). Development of duplex real - time RT - PCR based on Taqman technology for detecting simultaneously the genome of pan enterovirus and enterovirus 71. Journal of medical virology, 85(7), 1274-1279. http://dx.doi.org/10.1002/ jmv.23588

Jain, M., Nijhawan, A., Tyagi, A. K., \& Khurana, J. P. (2006). Validation of housekeeping genes as internal control for studying gene expression in rice by quantitative real-time PCR. Biochemical and biophysical research communications, 345(2), 646-651. http://dx.doi.org/10.1016/j.bbrc.2006.04.140

Kumar, K., Muthamilarasan, M., \& Prasad, M. (2013). Reference genes for quantitative real-time PCR analysis in the model plant foxtail millet (Setaria italica L.) subjected to abiotic stress conditions. Plant Cell, Tissue and Organ Culture (PCTOC), 115(1), 13-22. http://dx.doi.org/10.1007/s11240-013-0335-x

La Cruz, S., Lopez-Calleja, M. I., Alcocer, M., González, I., Martín, R., \& García, T. (2013). TaqMan real-time PCR assay for detection of traces of Brazil nut (Bertholletia excelsa) in food products. Food control, 140, 382-389. http://dx.doi.org/10.1016/j.foodcont.2013.01.053

Lee, J. M., Roche, J. R., Donaghy, D. J., Thrush, A., \& Sathish, P. (2010). Validation of reference genes for quantitative RT-PCR studies of gene expression in perennial ryegrass (Lolium perenne L.). BMC Molecular Biology, 11(1), 8. http://dx.doi.org/10.1186/1471-2199-11-8

Livak, K. J., \& Schmittgen, T. D. (2001). Analysis of relative gene expression data using real-time quantitative PCR and the 2- $\Delta \Delta$ CT method. methods, 25(4), 402-408. http://dx.doi.org/10.1006/meth.2001.1262

Mallona, I., Lischewski, S., Weiss, J., Hause, B., \& Egea-Cortines, M. (2010). Validation of reference genes for quantitative real-time PCR during leaf and flower development in Petunia hybrida. BMC Plant Biology, 10(1), 4. http://dx.doi.org/10.1186/1471-2229-10-4

Marshall, O. J. (2004). PerlPrimer: cross-platform, graphical primer design for standard, bisulphite and real-time PCR. Bioinformatics 20(15): 2471-2472. http://dx.doi.org/10.1093/bioinformatics/bth254

Mitchell, P. (2001). Microfluidics-downsizing large-scale biology. Nature biotechnology, 19(8), 717-721. http://dx.doi.org/10.1093/bioinformatics/bth254

Mullis, K. B., \& Faloona, F. A. (1987). Specific synthesis of DNA in vitro via a polymerase-catalyzed chain reaction. Methods in enzymology, 155, 335-350. http://dx.doi.org/10.1016/0076-6879(87)55023-6

Ng, C. T., Gilchrist, C. A., Lane, A., Roy, S., Haque, R., \& Houpt, E. R. (2005). Multiplex real-time PCR assay using Scorpion probes and DNA capture for genotype-specific detection of Giardia lamblia on fecal samples. Journal of clinical microbiology, 43(3), 1256-1260. http://dx.doi.org/10.1128/JCM.43.3.1256-1260.2005

Niu, J. Z., Dou, W., Ding, T. B., Yang, L. H., Shen, G. M., \& Wang, J. J. (2012). Evaluation of suitable reference genes for quantitative RT-PCR during development and abiotic stress in Panonychus citri (McGregor)(Acari: Tetranychidae). Molecular biology reports, 39(5), 5841-5849. http://dx.doi.org/10.1007/s11033-011-1394-x

Pabla, S. S., \& Pabla, S. S. (2008). Real-time polymerase chain reaction. Resonance, 13(4), 369-377. http://dx.doi.org/10.1007/s12045-008-0017-x

Petit, C., Pernin, F., Heydel, J. M., \& Délye, C. (2012). Validation of a set of reference genes to study response to herbicide stress in grasses. BMC research notes, 5(1), 18. http://dx.doi.org/10.1186/1756-0500-5-18

Pfaffl, M. W., Tichopad, A., Prgomet, C., \& Neuvians, T. P. (2004). Determination of stable housekeeping genes, differentially regulated target genes and sample integrity: BestKeeper-Excel-based tool using pair-wise correlations. Biotechnology letters, 26(6), 509-515. http://dx.doi.org/10.1023/B:BILE.0000019559.84305.47 
Ransbotyn, V., \& Reusch, T. B. (2006). Housekeeping gene selection for quantitative real - time PCR assays in the seagrass Zostera marina subjected to heat stress. Limnology and Oceanography: Methods, 4(10), 367-373. http://dx.doi.org/10.4319/lom.2006.4.367

Rebouças, E. D. L., Costa, J. J. D. N., Passos, M. J., Passos, J. R. D. S., Hurk, R. V. D., \& Silva, J. R. V. (2013). Real time PCR and importance of housekeepings genes for normalization and quantification of mRNA expression in different tissues. Brazilian Archives of Biology and Technology, 56(1), 143-154. http://dx.doi.org/10.1590/S1516-89132013000100019

Reid, K. E., Olsson, N., Schlosser, J., Peng, F., \& Lund, S. T. (2006). An optimized grapevine RNA isolation procedure and statistical determination of reference genes for real-time RT-PCR during berry development. BMC plant biology, 6(1), 27. http://dx.doi.org/10.1186/1471-2229-6-27

Rocha, A. J., Miranda, R., \& Cunha, R. M. S. (2014). Avaliação de DNA polimerases em ensaios de amplificação de microssatélites através do PowerPlex ${ }^{\circledR} 16$ BIO System. BBR-Biochemistry and Biotechnology Reports, 3(2), 1-8. http://dx.doi.org/10.5433/2316-5200.2014v3n2p1

Rocha, A. J., Soares, E. L., Costa, J. H., Costa, W. L., Soares, A. A., Nogueira, F. C., ... \& Campos, F. A. (2013). Differential expression of cysteine peptidase genes in the inner integument and endosperm of developing seeds of Jatropha curcas L.(Euphorbiaceae). Plant science, 213, 30-37. http://dx.doi.org/10.5433/2316-5200. $2014 v 3 n 2 p 1$

Romano, E., Brasileiro, A. C. M. (1998). Extração de DNA de Tecidos Vegetais. In A. C. M. Brasileiro, \& V. T. C. (Eds.), Carneiro Manual de transformações Genéticas De Plantas. Editora Embrapa: Brasília v. 40-43, 1998.

Saha, G. C., \& Vandemark, G. J. (2013). Stability of expression of reference genes among different Lentil (Lens culinaris) genotypes subjected to cold stress, white mold disease, and aphanomyces root rot. Plant Molecular Biology Reporter, 31(5), 1109-1115. http://dx.doi.org/10.1007/s11105-013-0579-y

Saiki, R. K., Scharf, S., Faloona, F., Mullis, K. B., Horn, G. T., Erlich, H. A., \& Arnheim, N. (1985). Enzymatic amplification of beta-globin genomic sequences and restriction site analysis for diagnosis of sickle cell anemia. Science, 230(4732), 1350-1354. http://dx.doi.org/10.1126/science.2999980

Sambrook, J., Fritsch, E. F., \& Maniatis, T. (1989). Molecular cloning (Vol. 2, pp. 14-9). New York: Cold spring harbor laboratory press.

Schmittgen, T. D., \& Livak, K. J. (2008). Analyzing real-time PCR data by the comparative CT method. Nature protocols, 3(6), 1101-1108. http://dx.doi.org/10.1038/nprot.2008.73

Schmittgen, T. D., \& Zakrajsek, B. A. (2000). Effect of experimental treatment on housekeeping gene expression: validation by real-time, quantitative RT-PCR. Journal of biochemical and biophysical methods, 46(1), 69-81. http://dx.doi.org/10.1016/S0165-022X(00)00129-9

Selim, M., Legay, S., Berkelmann-Löhnertz, B., Langen, G., Kogel, K. H., \& Evers, D. (2012). Identification of suitable reference genes for real-time RT-PCR normalization in the grapevine-downy mildew pathosystem. Plant cell reports, 31(1), 205-216. http://dx.doi.org/10.1007/s00299-011-1156-1

Suzuki, T., Higgins, P. J., \& Crawford, D. R. (2000). Control selection for RNA quantitation. Biotechniques, 29(2), 332-337.

Thellin, O., Zorzi, W., Lakaye, B., De Borman, B., Coumans, B., Hennen, G., ... \& Heinen, E. (1999). Housekeeping genes as internal standards: use and limits. Journal of biotechnology, 75(2), 291-295. http://dx.doi.org/10.1016/S0168-1656(99)00163-7

Tong, Z., Gao, Z., Wang, F., Zhou, J., \& Zhang, Z. (2009). Selection of reliable reference genes for gene expression studies in peach using real-time PCR. BMC Molecular Biology, 10(1), 71. http://dx.doi.org/10. 1186/1471-2199-10-71

Udvardi, M. K., Czechowski, T., \& Scheible, W. R. (2008). Eleven golden rules of quantitative RT-PCR. The Plant Cell Online, 20(7), 1736-1737. http://dx.doi.org/10.1105/tpc.108.061143

Vandesompele, J., De Preter, K., Pattyn, F., Poppe, B., Van Roy, N., De Paepe, A., \& Speleman, F. (2002). Accurate normalization of real-time quantitative RT-PCR data by geometric averaging of multiple internal control genes. Genome biology, 3(7), research0034. http://dx.doi.org/10.1186/gb-2002-3-7-research0034

VanGuilder, H. D., Vrana, K. E., \& Freeman, W. M. (2008). Twenty-five years of quantitative PCR for gene expression analysis. Biotechniques, 44(5), 619-626. http://dx.doi.org/10.2144/000112776 
Wong, M. L., \& Medrano, J. F. (2005). Real-time PCR for mRNA quantitation. Biotechniques, 39(1), 75-85. http://dx.doi.org/10.2144/05391RV01

Zheng, J., Li, J., Jiang, Y., Jin, J., Wang, K., Yang, R., \& Tan, W. (2011). Design of aptamer-based sensing platform using triple-helix molecular switch. Analytical chemistry, 83(17), 6586-6592. http://dx.doi.org/10. 2144/05391RV01

Zhong, H. Y., Chen, J. W., Li, C. Q., Chen, L., Wu, J. Y., Chen, J. Y., ... \& Li, J. G. (2011). Selection of reliable reference genes for expression studies by reverse transcription quantitative real-time PCR in litchi under different experimental conditions. Plant cell reports, 30(4), 641-653. http://dx.doi.org/10.1007/s00299-010 $-0992-8$

\section{Copyrights}

Copyright for this article is retained by the author(s), with first publication rights granted to the journal.

This is an open-access article distributed under the terms and conditions of the Creative Commons Attribution license (http://creativecommons.org/licenses/by/3.0/). 